\title{
Análise da viabilidade econômico-financeira da utilização de painéis solares fotovoltaicos em residências localizadas em Mossoró-RN
}

\author{
Abner Vinicius de Lucena Sousa ${ }^{[1]}$, Francisco Magno Monteiro Sobrinho ${ }^{[2]}$ \\ [1] Universidade Federal Rural do Semi-árido; sousa.abner@hotmail.com \\ ${ }^{[2]}$ Universidade Federal Rural do Semi-árido; magno.monteiro@ufersa.edu.br \\ Recebido: 25/06/2019; \\ Aceito: 08/08/2019; \\ Publicado: 07/10/2019.
}

Resumo: A discussão acerca de novos meios de produção de energia elétrica através do uso de fontes renováveis é tema atual e relevante no âmbito nacional, justificando pesquisas científicas que demonstram a funcionalidade e as aplicações dos variados sistemas de geração de energia limpa. Nesse contexto, o presente trabalho propôs analisar a viabilidade econômico financeira da utilização de um sistema fotovoltaico instalado no telhado de uma residência na cidade de Mossoró no interior do Rio Grande do Norte. O estudo foi realizado com base nos dados de consumo da residência para o dimensionamento e escolha dos equipamentos que compõem o sistema fotovoltaico, simulação do funcionamento do sistema para os primeiros 25 anos de vida útil levando em consideração fatores como a perda de eficiência ao longo do tempo e a irradiação incidente sobre os módulos, análise econômica dos investimentos com base em técnicas de orçamento de capital, desde a simples até uma mais precisa e exposição dos resultados. Todos os parâmetros analisados neste estudo apontaram para um investimento vantajoso economicamente onde os tempos de retorno do investimento, payback simples e descontado (12,405 e 18,167 anos, respectivamente), foram inferiores a vida útil média do sistema fotovoltaico, o Custo da Energia Conservada (CEC) apontou para um investimento atrativo financeiramente, uma vez que seu cálculo resultou em um valor médio $14,5 \%$ abaixo de $\mathrm{R} \$ 0,38968$, preço médio do kWh para o ano de 2018.

Palavras-chave: sistema fotovoltaico; viabilidade econômico financeira; geração distribuída; energia solar fotovoltaica

\section{INTRODUÇÃO}

$\mathrm{A}^{2}$ busca incessante por formas de economizar capital chega a atingir até o setor residencial quando se trata do consumo de energia elétrica, o aumento persistente da tarifa de energia elétrica desde a implementação do sistema de bandeiras tarifárias tem forçado o setor residencial brasileiro a explorar novos meios de economizar com energia elétrica além de adotar um estilo de consumo moderado.

Paralelo a este aspecto, está a busca contínua por fontes de energia renováveis que, além de garantir a geração de energia a partir de uma fonte inesgotável, preocupa-se com a preservação ambiental visto que, o Brasil, mesmo apresentando mais da metade da sua matriz elétrica composta por centrais hidrelétricas, ainda é amparado por fontes de energia esgotáveis, tais como carvão, gás natural e derivados do petróleo. Nesse cenário, uma das formas mais promissoras de contornar esse problema e que vem sendo bastante veiculada é o aproveitamento da energia solar, fonte renovável, inesgotável e gratuita [1].

Dentre as variadas formas de geração de energia elétrica a partir da fonte solar, no Brasil, destaca-se a geração a partir de placas solares fotovoltaicas, que geram energia elétrica através de um material semicondutor que apresenta o efeito fotovoltaico, fenômeno definido como o aparecimento de uma tensão elétrica no material semicondutor após ser exposto a luz. No contexto nacional, o Brasil apresenta enorme potencial para o 
aproveitamento da fonte solar, uma vez que o país apresenta médias de incidência de radiação solar bem superiores que países onde a tecnologia fotovoltaica é amplamente utilizada.

A energia solar participava com apenas $0,6 \%$ do total de capacidade instalada no Brasil em 2017, mesmo significando ainda apenas uma pequena fatia do total de capacidade instalada do Brasil, a geração solar fotovoltaica merece destaque em consequência do salto obtido em relação a 2016, onde a potência instalada passou de 24 MW para 935 MW [1].

Os recentes avanços tecnológicos na área de manipulação dos semicondutores, em especial do silício, ajudaram a reduzir o custo final de mercado dos sistemas fotovoltaicos, e essa diminuição dos preços é o que mais chama a atenção para o impulsionamento do mercado fotovoltaico. Ademais, um sistema fotovoltaico apresenta uma série de vantagens, entre elas, baixa manutenção, a possibilidade de usar sistemas para atender a todos os tipos de potência desde o setor residencial até o industrial, e a característica modular do sistema fotovoltaico permite que o mesmo seja instalado integralizado a estrutura da edificação não necessitando de espaço extra para tal, além de possibilitar a ampliação do sistema de acordo com as necessidades do consumidor.

Com o intuito de garantir a eficiência energética das edificações e, além disso, assegurar a inserção da fonte solar na matriz elétrica brasileira, o estudo acerca de sistemas fotovoltaicos se torna imprescindível no ramo da academia e também para o setor de construção civil.

O objetivo deste trabalho é verificar a viabilidade econômico-financeira da utilização de sistemas fotovoltaicos no setor residencial da região de Mossoró-RN, analisando o período de tempo decorrido até que o investimento se transforme em lucro e examinando o custo da energia gerada pelos painéis

\section{FUNDAMENTAÇÃO TEÓRICA}

Existem diversos tipos de fontes de energias renováveis, eles se destacam principalmente por oferecerem um impacto ambiental mínimo e, ainda por cima, garantem diversas vantagens à seu usuário. Dentre as fontes de energias renováveis existentes, a solar vem se destacando nos últimos anos com o avanço da tecnologia e a consequente diminuição dos preços de instalação e manutenção. Dessa forma, um estudo acerca da viabilidade econômico-financeira da utilização da energia solar fotovoltaica em residências faz-se necessário. Nesta seção serão discutidos de forma concisa os assuntos cruciais para o entendimento do trabalho.

\subsection{Cenário energético brasileiro atual}

O Brasil, país onde a geração de energia elétrica proveniente dos recursos hídricos ocupa o maior percentual da geração total, atingiu 588,0 TWh de produção de energia elétrica a partir de centrais de serviço público e autoprodutores em 2017. O que coloca o país em posição de destaque, uma vez que as fontes de energia renováveis representam $80,4 \%$ da oferta interna de eletricidade [1].

Ainda de acordo com [1], independentemente de a geração elétrica a partir de fontes não renováveis sofrer um crescimento de 1,2\% em 2017 com relação a 2016, a geração de autoprodutores participou com 16,5\% (96,8 TWh) do total de energia elétrica produzida no Brasil, desse total, 55,4 TWh não foram injetados na rede elétrica de distribuição, ou seja, a energia elétrica é consumida pela própria instalação geradora.

O consumo final de energia elétrica no país foi de 526,2 TWh, representando uma expansão de 1,2\% em relação a 2016. Desse montante, o setor residencial foi responsável por 25,5\% do consumo total de eletricidade no país, atrás somente do setor industrial com 37,7\%, como é possível ver na Figura 1 [1]. Como o setor residencial ocupa uma fatia considerável do consumo interno de energia elétrica, os gastos com manutenção e investimento, principalmente na expansão das linhas de transmissão, nesse setor, instituem um aumento considerável no preço de produção da energia elétrica. 


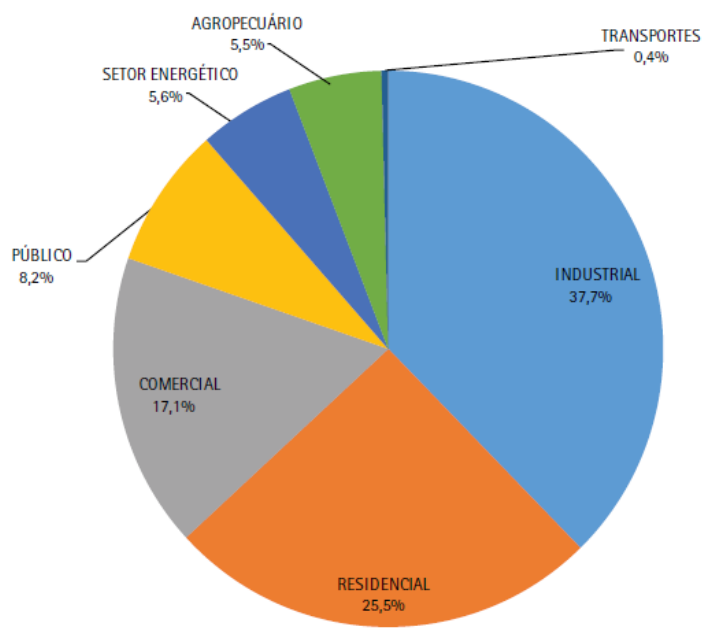

FIGURA 1. Participação setorial no consumo da eletricidade [1].

É partindo desse cenário que as energias renováveis, principalmente a eólica e solar ganham espaço, uma vez que prometem produção de energia satisfatória para o setor residencial com impacto ambiental mínimo ou nulo, uma vez que painéis solares podem ser instalados como parte integrante da estrutura de telhados.

A capacidade total instalada de energia elétrica do Brasil em 2017, incluindo centrais de serviço público e autoprodutores, chegou a marca de $157.112 \mathrm{MW}$, conferindo um acréscimo de $6.775 \mathrm{MW}$ em relação a 2016. Como o Brasil é um país que possui matriz energética predominantemente hídrica, as centrais hidrelétricas contribuíram com 49,5\% desse aumento na capacidade instalada, ou seja, 3.350 MW. Entretanto, o maior destaque desse acréscimo na capacidade instalada se dá para a geração de energia elétrica solar fotovoltaica que, mesmo contribuindo com apenas $0,6 \%$ do total da capacidade instalada do Brasil saltou de 24 MW de potência instalada em 2016 para 935 MW em 2017 [1].

\subsection{Geração distribuída}

É através do uso da energia elétrica que as sociedades se desenvolvem e prosperam, ela é indispensável para o desenvolvimento econômico e técnico no cenário mundial atual, além disso, é responsável pela disseminação de informação e difusão de conhecimento.

A geração distribuída pode ser definida como a geração de energia que se localiza próximo da unidade consumidora e, independentemente de seu tamanho e proveniente das células fósseis, da energia eólica, e como foco principal deste trabalho, da energia solar fotovoltaica. No momento presente, a busca por novas tecnologias e a garantia da preservação do meio ambiente são pautas pertinentes quando se trata do processo de produção ou distribuição de energia elétrica, assim, a geração distribuída tem sido citada como alternativa aos tradicionais meios de produção e distribuição de energia elétrica [2].

A geração distribuída oferece diversas vantagens para o setor elétrico brasileiro e, a principal delas é a coincidência espacial entre geração e consumo de energia, o que acarreta em uma minimização das perdas de cargas por transmissão, como ocorre nas centrais geradoras de eletricidade tradicionais [3].

Uma característica relevante da geração distribuída é a capacidade de incluir potências cada vez menores, assim, a geração descentralizada pode ocorrer em locais onde normalmente não seria possível ser instalada uma usina geradora de energia do tipo convencional, dessa forma, a geração distribuída vem como uma alternativa para ajudar a aumentar a distribuição geográfica de geração de energia elétrica em regiões de difícil acesso [4].

No sistema atual de geração e distribuição de energia elétrica, é necessário transportar a energia gerada na usina até o setor residencial através de linhas de transmissão que requerem uma alta tensão, pois ocorrem perdas devido a impedância de alimentadores e transformadores. Essas perdas podem ser significativas em condições especiais de operação e, assim, as concessionárias acabam por passar para o consumidor o custo por essas perdas na forma de aumento de tarifas.

Esse e outros fatores como a crescente preocupação com a sustentabilidade, que juntamente com o avanço tecnológico promove soluções para minimizar o impacto ambiental no processo de geração de energia e promove um melhor aproveitamento das fontes renováveis de energia, fazem com que a geração distribuída 
seja uma solução para tais problemas, pois, além de utilizar uma fonte renovável para gerar energia elétrica, a introdução da geração distribuída garante a redução de perdas pois não há a necessidade de haver linhas de transmissão, uma vez que a energia é gerada junto ao ponto de consumo [4].

No Brasil, o incentivo para a utilização da geração distribuída é feito pelos próprios consumidores, dessa maneira, a inserção da geração distribuída conectada à rede acarreta em diminuição de gastos do governo com obras para a construção de novas centrais de geração de energia elétrica, além de auxiliar na diminuição da demanda de energia em períodos de pico [5].

No presente momento, a geração fotovoltaica juntamente com a geração eólica constituem a maior parcela dos sistemas de geração distribuídas no Brasil. Em 2017, a micro e mini geração distribuída atingiu 359,15 GWh com uma potência instalada de 246,1 MWh, onde a geração solar fotovoltaica se destaca por contribuir com 165,87 GWh e 174,5 MWh de geração e potência instalada respectivamente. O Rio Grande do Norte soma apenas 4,7 MWh do total de capacidade instalada de micro e mini geração distribuída [1].

Devido a variados incentivos para a disseminação da tecnologia solar fotovoltaica na geração distribuída, esse trabalho terá como foco principal analisar a viabilidade econômica da utilização da mesma na região do interior do Rio Grande do Norte.

Graças a recentes incentivos governamentais e avanço da tecnologia, a expansão da geração fotovoltaica ganha visibilidade no mercado e, consequentemente, também gera uma redução nos preços de instalação, manutenção e produção de energia elétrica a partir de módulos fotovoltaicos.

O principal componente dos módulos fotovoltaicos é o silício, sua exploração e manipulação se dão de variadas formas, e assim, existem diversos tipos de módulos fotovoltaicos disponíveis no mercado. O silício cristalino, mais utilizado atualmente na produção de módulos fotovoltaicos, domina $85 \%$ do mercado fotovoltaico por ser considerada uma tecnologia confiável e possuir a melhor eficiência comercialmente disponível [6].

Os sistemas fotovoltaicos conectados à rede são vantajosos pois dispensam o uso de acumuladores, pois a energia produzida por esses sistemas pode tanto ser consumida diretamente pela carga ou injetada na rede elétrica tradicional a fim de ser consumida pelas demais unidades consumidoras conectadas a rede de distribuição de energia elétrica [6]. Muitas das vezes, esse tipo de sistema funciona de forma complementar ao sistema elétrico já existente pois pode contar com ele como um backup quando a demanda supera a geração do sistema fotovoltaico, dessa forma, não existe a necessidade de superdimensionamento do sistema para atender a demanda de energia elétrica em períodos de baixa incidência solar, por exemplo [3].

Sistemas fotovoltaicos de baixa potência instalada, como geralmente são encontrados no setor residencial, são enquadrados como sistemas de micro e mini geração e são regulamentados pela ANEEL (Agência Nacional de Energia Elétrica) através da Resolução Normativa $N^{\circ} 482 / 2012$, que estabelece as condições gerais para o acesso de micro e mini geração distribuídas aos sistemas de distribuição de energia elétrica e o sistema de compensação de energia elétrica [7].

\subsubsection{Micro e mini geração distribuída}

Micro geração distribuída é toda central geradora de eletricidade, com potência instalada menor ou igual a $75 \mathrm{KW}$ e que pode utilizar como base para a produção de energia elétrica a fonte hidráulica, solar, eólica e biomassa de acordo com regulamentação da ANEEL, conectada na rede de distribuição por meio de instalações de unidades consumidoras [6].

Mini geração distribuída é toda central geradora de eletricidade, com potência instalada superior a $75 \mathrm{KW}$ e menor ou igual a 3 MW e que pode utilizar como base para a produção de energia elétrica a fonte hidráulica, solar, eólica e biomassa de acordo com regulamentação da ANEEL, conectada na rede de distribuição por meio de instalações de unidades consumidoras [6].

\subsubsection{Sistema de compensação de energia elétrica}

Também intitulado de net metering, nesse sistema, o consumidor que possuir um sistema de geração distribuída localizado em sua própria unidade consumidora gozará de um medidor de energia bidirecional onde a energia ativa injetada pela unidade consumidora na rede é cedida, na forma de empréstimo, a concessionária e posteriormente compensada com o consumo de energia elétrica dessa mesma unidade consumidora ou de qualquer outra unidade consumidora, desde que esteja sob posse do mesmo titular. Para instalações de baixa tensão a medição bidirecional pode ser realizada através de dois medidores unidirecionais: um para a energia consumida e outro para a energia injetada [7]. 
Nesse sistema, quando a energia elétrica proveniente da geração fotovoltaica não é consumida de imediato, ela é cedida para a rede de distribuição por meio de empréstimo gratuito, na forma de excedente, ou seja, a diferença positiva entre a energia injetada e a consumida, e o medidor da unidade consumidora opera no sentido contrário do convencional e mede apenas a diferença entre a energia consumida da injetada. Este sistema é exemplificado na Figura 2 [6].

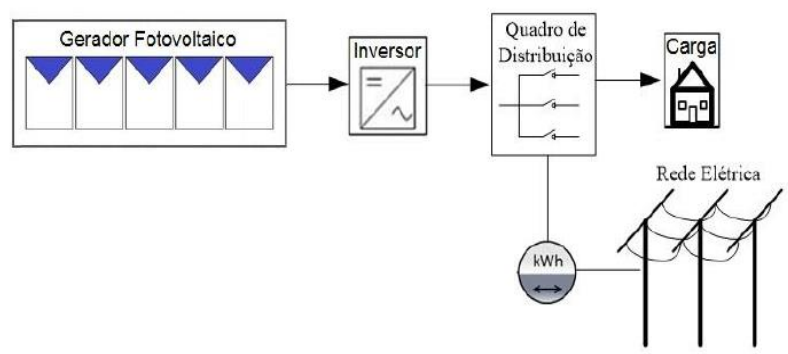

FIGURA 2. Sistema de geração fotovoltaico conectado à rede com medidor de energia bidirecional [6].

Todos os custos referentes à adequação do sistema de medição, ou seja, da aquisição do medidor bidirecional, necessário para implantar o sistema de compensação de energia elétrica, são de responsabilidade da unidade consumidora. Além disso, os créditos de energia ativa gerada por meio dos sistemas de compensação de energia elétrica expirarão 60 meses após a data do faturamento [7].

Esse sistema enfrenta dificuldades em relação ao valor apropriado da energia injetada na rede de distribuição e as taxas associadas a ela, uma vez que as concessionárias cobram valores diferentes para o kWh em diferentes horários do dia, pois a energia elétrica tem maior valor em horários onde a demanda por energia elétrica é crítica [3]. Isto posto, uma solução viável para contornar essa dificuldade é a criação de um setor especifico para o controle da geração distribuída que encontra-se conectada à rede.

\subsection{Radiação solar}

Considerando a escala terrestre de tempo, o sol é uma fonte inesgotável de energia, tanto como fonte de calor como de luz, assim sendo, é hoje uma das alternativas energéticas mais promissoras para o progresso da exploração de recursos para a geração de energia [6].

A radiação solar é a energia gerada a partir de reações de fusão termonuclear que ocorrem no núcleo do sol e produzem radiação eletromagnética em várias frequências ou comprimentos de onda, a radiação ocorre diretamente da fonte para fora em todas as direções e essas ondas não necessitam de um meio material para se propagar, ou seja, elas podem viajar através do vácuo no espaço até alcançar a terra [6].

De acordo com [6], a densidade média anual do fluxo energético proveniente da radiação solar sobre um plano perpendicular à direção da propagação dos raios solares no topo da atmosfera terrestre recebe o nome de Constante Solar e corresponde ao valor de $1.367 \mathrm{~W} / \mathrm{m} 2$. Considerando que o raio médio da Terra é de $6.371 \mathrm{~km}$ e considerando o valor da irradiância de $1.367 \mathrm{~W} / \mathrm{m} \neg 2$ incidindo sobre a área projetada da Terra, conclui-se que a potência total disponibilizada pelo Sol à Terra é de aproximadamente 174.000 TW. Uma parte dessa radiação solar é refletida ou absorvida pela superfície terrestre e pela atmosfera, dessa forma, cerca de 94.000 TW de potência chegam efetivamente a superfície terrestre.

Segundo [1], o consumo final total de todas as fontes de energia em 2017 no Brasil foi de aproximadamente $3.008 \mathrm{TWh}$, então, em um intervalo de apenas uma hora, a energia proveniente do sol equivale a 31 vezes o consumo anual de energia do Brasil. Este exemplo serve para mostrar o potencial da energia solar e como ele ainda é pouco explorado atualmente.

De acordo com [8], a participação das hidroelétricas na matriz elétrica brasileira torna o sistema elétrico brasileiro singular no que tange aos aspectos de impactos ambientais. Porém, por se tratar de uma fonte renovável de energia, ela está sujeita a influência de fatores climáticos de modo que a energia armazenada possa atingir valores críticos em períodos de seca, diminuindo a oferta de energia e acarretando num aumento do preço da energia do país. Dessa forma, o aproveitamento da fonte solar se apresenta como excelente opção de suporte para as fontes já consolidadas no brasil uma vez que o recurso solar não apresenta grandes impactos ambientais como as hidroelétricas, possui alta capacidade de geração de energia e se utiliza de uma fonte inesgotável, o sol. 
As nuvens são o principal fator modulador da radiação pois suas propriedades óticas produzem um espalhamento eficiente da radiação solar, além disso, outros fatores como altitude, pressão atmosférica e relevo tornam uma região única, e assim, cada região do país possui um rendimento diferente para a tecnologia fotovoltaica [8].

Com o auxílio do software RADIASOL 2, desenvolvido pelo Laboratório de Energia Solar - LABSOL da Universidade Federal do Rio Grande do Sul foi possível obter dados sobre a irradiação solar média para todos os meses de 2018, Figura 3. A partir desses dados é possível constatar que os níveis de irradiação para a cidade de Mossoró-RN estão acima da média brasileira [5 kWh/(m2.dia)] em maior parte do ano.

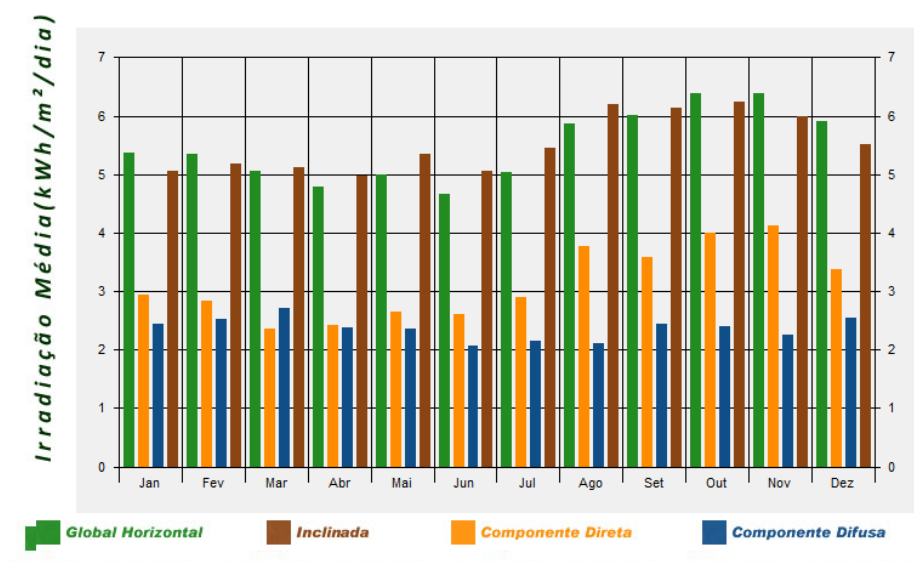

FIGURA 3. Gráfico das radiações incidentes sobre a cidade de Mossoró-RN (RADIASOL 2, Laboratório de Energia solar, UFRGS, 2019).

Os projetos de sistemas fotovoltaicos normalmente exigem uma irradiação de no mínimo 3 a 4 $\mathrm{kWh} /(\mathrm{m} 2$.dia) [6], portanto, a região da cidade de Mossoró no interior do Rio Grande do Norte é um local propício para a instalação desse tipo de sistema.

Para o correto dimensionamento de um sistema fotovoltaico é necessário conhecer os dados de radiação global horizontal incidente no local de instalação dos módulos e conhecer também os dados de radiação incidente sobre o plano inclinado dos módulos solares [6]. Além disso, com os estudos contínuos acerca da radiação solar é possível obter a geração de séries históricas contendo dados cada vez mais confiáveis e detalhados.

\subsection{Análise econômica}

Um estudo de análise de viabilidade econômica tem como objetivo avaliar o orçamento de um sistema, sua vida útil e o tempo de retorno do investimento [9]. Para realizar tal análise faz-se necessário a utilização de métodos de orçamento de capital que, através de indicadores econômicos, vão atestar a viabilidade de instalação de um empreendimento, considerando os investimentos iniciais, custos de operação e manutenção e os lucros obtidos em um determinado período.

Este trabalho tem como objetivo analisar a viabilidade econômica da utilização da energia solar fotovoltaica na cidade de Mossoró-RN com o intuito de inserir a fonte fotovoltaica na matriz elétrica brasileira e promover o desenvolvimento sustentável e social em residências unifamiliares, para tal, foram utilizados como critério para atestar a viabilidade econômica, as técnicas de orçamento de capital payback simples, payback descontado e o Custo da Energia Conservada.

\subsubsection{Payback simples}

O payback é uma técnica de orçamento que analisa o tempo necessário para que a empresa recupere o seu investimento inicial em um projeto, esse tempo é chamado de "período de payback" e é calculado a partir das entradas de caixa do empreendimento e do investimento inicial [10].

O período de payback é encontrado dividindo-se o investimento inicial pela entrada de caixa anual, assim, o resultado será dado em anos. O payback simples é uma ferramenta versátil para atestar se um empreendimento é viável ou não, porém, desconsidera o valor do dinheiro no tempo e, além disso, desconsidera as entradas de fluxo de caixa após a recuperação do investimento [10]. 
Por se tratar de um método simples de análise econômica, ele não é o suficiente para atestar a viabilidade de um empreendimento e deve ser utilizado juntamente com outros métodos.

\subsubsection{Payback descontado}

O payback descontado é muito semelhante ao payback simples, também analisa o período de retorno do investimento de um empreendimento, a diferença está no fato de que o payback descontado considera o valor do dinheiro variando no tempo. Ele atualiza os valores dos fluxos de caixa para o valor presente a uma taxa de atratividade e só então calcula o período para a recuperação do investimento inicial. O critério para análise do payback descontado é que, quanto mais tempo for preciso para recuperar os investimentos, maior é a possibilidade de imprevistos acontecerem e, assim, o empreendimento se torna inviável, então, quanto menor o período de payback menor a exposição ao risco e mais viável se torna o empreendimento [10].

A principal vantagem do payback descontado sobre o payback simples são que, seu valor pode ser interpretado como o prazo de recuperação do capital investido remunerado de acordo com o custo de capital do projeto e valores situados além da data do payback descontado serão contabilizados como lucros extras.

\subsubsection{Custo da energia conservada (CEC)}

O custo da energia conservada avalia a eficiência econômica de um empreendimento de geração de energia e para tanto, o valor encontrado do CEC deve ser menor que a tarifa de um $\mathrm{kWh}$ de energia para que o investimento seja considerado interessante e viável economicamente. Tratando de uma forma mais simplificada, o CEC vai dizer se é mais vantajoso consumir a energia, sem a implementação de um sistema de geração, ou economizá-la, investindo em um sistema de geração de energia [11].

Usualmente, os resultados do CEC são semelhantes ao do Valor Presente Líquido (VPL) e da Taxa Interna de Retorno (TIR), porém, o cálculo do CEC é menos complicado e seu resultado mais simples de analisar.

Outra vantagem do uso do CEC é que ele não depende do valor presente nem dos valores futuros do custo do $\mathrm{kWh}$, ou seja, caso o valor encontrado seja maior que o valor atual do $\mathrm{kWh}$, o empreendimento ainda pode ser viável quando analisado a longo prazo.

O cálculo do CEC considera os investimentos, energia economizada no período de um ano, vida útil do empreendimento e taxas de desconto e é determinado através da Equação 1 [11].

$$
\mathrm{CEC}=\left(\frac{\mathrm{TCC}}{\Delta \mathrm{E}}\right) \times\left(\frac{\mathrm{d}}{\left(1-(1+\mathrm{d})^{-\mathrm{n}}\right)}\right)
$$

Onde:

$\mathrm{CEC}=$ Custo da energia conservada $[\mathrm{R} \$ / \mathrm{kWh}]$;

$\mathrm{TCC}=$ Custo em $\mathrm{R} \$$ da implementação da medida de conservação de energia [MCE];

$\Delta \mathrm{E}=$ Energia economizada num período de um ano [ $\mathrm{kWh} / \mathrm{ano}]$;

$\mathrm{n}$ = Vida útil da MCE [anos];

$\mathrm{d}$ = Taxa de desconto em base anual do Índice Nacional de Custo da Construção [INCC - IBGE].

\section{METODOLOGIA}

O método do presente trabalho é o estudo de caso, utilizando-se de simulação computacional dos módulos fotovoltaicos e seguinte análise econômica dos investimentos utilizando técnicas de orçamento de capital. A metodologia deste artigo foi dividida conforme o fluxograma na Figura 4.

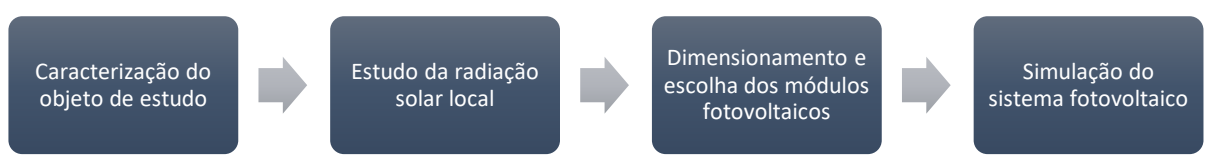

FIGURA 4. Fluxograma da metodologia (Autoria própria).

\subsection{Caracterização do objeto de estudo}

O objeto de estudo deste trabalho é uma residência familiar localizada na cidade de Mossoró-RN, a mesma conta com $150 \mathrm{~m}^{2}$ de área construída, o sistema fotovoltaico a ser instalado na residência será do tipo on grid, ou seja, não há a necessidade de baterias para o armazenamento de energia elétrica, dessa forma, toda a produção 
de energia elétrica gerada pelos painéis fotovoltaicos é injetado na rede e, dessa forma, o excedente é contabilizado na forma de créditos de energia.

Em termos de radiação solar, a residência localiza-se na região metropolitana da cidade de Mossoró, área geográfica com altos índices de incidência solar, geralmente superiores à média brasileira, além disso, para esse estudo de caso desconsiderou-se o efeito de obstruções que possam causar sombreamento sobre os painéis.

Para a captação de energia solar no hemisfério sul, usualmente recomenda-se a orientação dos painéis exatamente ao norte e uma inclinação de acordo com a latitude, no caso da cidade de Mossoró, através do uso do software RADIASOL 2, foi determinado que a melhor inclinação para a máxima eficiência dos painéis fotovoltaicos é de $10^{\circ}$, além disso, a cobertura da residência analisada apresenta uma área satisfatória para a instalação do sistema fotovoltaico.

A residência objeto de estudo possui um consumo médio mensal de 451,67 kWh levando-se em consideração o ano de 2018, um pouco acima da média brasileira que foi de 330,2 kWh [12], desta maneira, o valor médio da conta de energia elétrica da residência objeto estudo é R \$319,12. A Tabela 1 ilustra, em detalhes, os dados de consumo, preço do kWh e preço final da conta de energia.

TABELA 1. Consumo, preço do kWh e preço da conta de energia para 2018 (Autoria própria).

\begin{tabular}{cccccccc}
\hline Mês & $\begin{array}{c}\text { Consumo } \\
{[k W h]}\end{array}$ & $\begin{array}{c}\text { Preço } \\
k W h \\
{[R \$ / k W h]}\end{array}$ & $\begin{array}{c}\text { Preço da } \\
\text { conta } \\
{[R \$]}\end{array}$ & Mês & $\begin{array}{c}\text { Consumo } \\
{[k W h]}\end{array}$ & $\begin{array}{c}\text { Preço } \\
k W h \\
{[R \$ / k W h]}\end{array}$ & $\begin{array}{c}\text { Preço da } \\
\text { conta } \\
{[R \$]}\end{array}$ \\
\hline Jan & 501 & 0,6917 & 346,52 & Jul & 450 & 0,7069 & 318,09 \\
\hline Fev & 397 & 0,6740 & 267,58 & Ago & 402 & 0,7337 & 294,96 \\
\hline Mar & 435 & 0,6971 & 303,23 & Set & 469 & 0,7371 & 345,69 \\
\hline Abr & 473 & 0,6017 & 284,6 & Out & 466 & 0,7254 & 338,02 \\
\hline Mai & 493 & 0,7062 & 348,14 & Nov & 432 & 0,7590 & 327,88 \\
\hline Jun & 478 & 0,7207 & 344,48 & Dez & 424 & 0,7317 & 310,26 \\
\hline
\end{tabular}

\subsection{Estudo da radiação solar local}

Para o estudo da radiação solar na cidade de Mossoró-RN, utilizou-se o software RADIASOL 2, que é um programa que compõe o SOLARCARD, pacote de programas produzido pelo LABSOL da UFRGS visando o projeto de sistemas solares e seus respectivos componentes. A principal característica desses programas é sua interface bastante intuitiva e a necessidade de poucos dados de entrada para simular o comportamento real de cada componente de um sistema solar.

De acordo com os dados do RADIASOL 2, a irradiação média diária sobre o plano inclinado fica entre 5 a $6 \mathrm{kWh} / \mathrm{m} 2$.dia. Considerando apenas este dado de radiação solar já seria possível afirmar que a instalação do sistema solar fotovoltaico é viável, visto que, um projeto de sistema solar fotovoltaico usualmente exige níveis de irradiação na ordem de 3 a 4 kWh/m2.dia [6]. Porém, outros fatores são necessários serem levados em conta quando se dimensiona um sistema fotovoltaico, como a posição de instalação dos painéis na cobertura da edificação, possíveis obstruções que causem sombreamento nos painéis, dentre outros fatores. Para este estudo de caso considerou-se que a residência escolhida enquadra-se nos padrões aceitáveis para estes fatores. Na Tabela 2 encontram-se descritos os dados de irradiação solar sobre o plano inclinado dos painéis a serem instalados na residência estudada.

TABELA 2. Irradiação média mensal sobre o plano inclinado (Autoria própria).

\begin{tabular}{cccc}
\hline Mês & $\begin{array}{c}\text { Irradiação } \\
{[k W h /(m 2 . d i a)]}\end{array}$ & Mês & $\begin{array}{c}\text { Irradiação } \\
{[k W h /(m 2 . d i a)]}\end{array}$ \\
\hline Jan & 5,08 & Jul & 5,45 \\
\hline Fev & 5,22 & Ago & 6,20 \\
\hline Mar & 5,09 & Set & 6,13 \\
\hline Abr & 4,99 & Out & 6,24 \\
\hline Mai & 5,34 & Nov & 6,02 \\
\hline Jun & 5,06 & Dez & 5,53 \\
\hline
\end{tabular}




\subsection{Dimensionamento e escolha dos módulos fotovoltaicos}

Para a escolha dos módulos fotovoltaicos que serão utilizados no telhado da residência de estudo foi necessário escolher dentre a variedade de produtos e marcas disponíveis no mercado, analisando a disponibilidade do produto na região ou em suas proximidades e pesquisando preços com intuito de tornar o sistema mais atrativo economicamente. Dessa forma, foi escolhido o modelo CS6P-260P da empresa Canadian Solar, o módulo é produzido com silício policristalino, possui potência nominal máxima de $260 \mathrm{~W}$ e eficiência de $16,16 \%$. Além disso, também foi levado em consideração a reputação da empresa para a escolha do módulo, a Canadian Solar possui mais de 10 anos de experiência no mercado internacional de energia fotovoltaica.

Para a determinação da potência de pico do sistema fotovoltaico necessária para suprir a residência de estudo utilizou-se de simulação online no portal eletrônico Blue Sol, inserindo os dados de consumo mensal médio da residência em kWh e a localização geográfica da mesma. Assim, a potência de pico do sistema fotovoltaico a ser instalado é de $3,285 \mathrm{kWp}$.

A seguir, para saber a quantidade de painéis necessários, divide-se o valor da potência de pico do sistema pela potência nominal da placa, obtendo-se o valor de 12,63, valor arredondado para 13. Assim a potência de pico instalada será de $3,38 \mathrm{kWp}$. O inversor a ser utilizado nesse sistema foi escolhido levando-se em consideração a potência total do sistema, posto isto, foi selecionado o inversor da marca Phb de $3 \mathrm{~kW}$ de potência nominal modelo PHB3000-SS com 97\% de eficiência em conversão de energia. As 13 placas a serem instaladas no telhado da residência ocupam uma área de, aproximadamente, $21 \mathrm{~m}^{2}$, dessa forma, a residência estudada possui área satisfatória para a instalação do sistema.

\subsection{Simulação do sistema fotovoltaico}

Para simular a atividade de geração de energia elétrica do empreendimento ao longo de sua vida útil utilizou-se a Equação 2 [13]. Onde é possível projetar a média de geração elétrica a partir do sistema fotovoltaico com base na irradiação local incidente no plano das placas e na potência instalada total do sistema.

$$
\mathrm{P}_{\mathrm{FV}}=\frac{\mathrm{E} \cdot \mathrm{G}}{\mathrm{H}_{\mathrm{TOT}} \cdot \mathrm{PR}}
$$

Onde:

$\mathrm{P}_{\mathrm{FV}}=$ Potência instalada total $[\mathrm{kWp}]$;

$\mathrm{E}=$ Energia elétrica média diária gerada pelo sistema fotovoltaico $[\mathrm{kWh} / \mathrm{dia}]$;

$\mathrm{G}=$ Irradiação em condição de testes padrão [1kW/m2];

$\mathrm{H}_{\text {TOT }}=$ Irradiação solar incidente sobre o plano dos módulos fotovoltaicos $[\mathrm{kWh} /(\mathrm{m} 2 . d i a)]$;

PR = Taxa de desempenho do sistema fotovoltaico [75\% valor comumente utilizado].

A Tabela 3 ilustra os dados obtidos para a geração de energia elétrica do sistema fotovoltaico no primeiro ano.

TABELA 3. Projeção da geração de eletricidade no primeiro ano (Autoria própria).

\begin{tabular}{cccc}
\hline Mês & $\begin{array}{c}\text { Geração } \\
\text { mensal }[\mathrm{kWh}]\end{array}$ & Mês & $\begin{array}{c}\text { Geração } \\
\text { mensal }[\mathrm{kWh}]\end{array}$ \\
\hline Jan & 386,334 & Jul & 414,4725 \\
\hline Fev & 396,981 & Ago & 471,51 \\
\hline Mar & 387,0945 & Set & 466,1865 \\
\hline Abr & 379,4895 & Out & 474,552 \\
\hline Mai & 406,107 & Nov & 457,821 \\
\hline Jun & 384,813 & Dez & 420,5565 \\
\hline
\end{tabular}

A partir dos dados de geração obtidos na Tabela 3, pode-se notar que o total de geração nesse ano alcançou a marca de 5045,918 kWh.

Durante a vida útil de um painel fotovoltaico o mesmo pode perder sua eficiência em geração de energia, é por esse motivo que os fabricantes anunciam de forma pessimista que a vida útil dos painéis fica em torno de 25 anos, porém, no decorrer desse tempo, um módulo solar perde, em média, somente $20 \%$ de sua eficiência. Para a obtenção de dados mais representativos, é necessário levar em conta a perda de eficiência dos módulos 
ao longo do tempo, dessa forma, adotou-se como taxa de perda de eficiência dos módulos o valor de $0,5 \%$ ao ano.

$\mathrm{O}$ valor de venda da energia gerada é diferente do valor do $\mathrm{kWh}$ vendido pela concessionária do estado, esses valores são definidos pela Câmara de Comercialização de Energia Elétrica (CCEE) em função dos dados de Preço de Liquidação das Diferenças (PLD) [14]. Para o estudo da residência escolhida foi selecionado o valor médio de preço do kWh gerado para o ano de 2018 para o patamar médio do submercado Nordeste, apresentando valor de $\mathrm{R} \$ 0,38968$. Adotando esse valor como faixa de preço fixo para a venda de energia elétrica foi possível fazer as projeções de receitas anuais para os 25 anos de vida útil do sistema.

A Tabela 4 reflete os dados de economia gerada ano a ano para o sistema fotovoltaico proposto, tomando em consideração a perda de eficiência dos módulos fotovoltaicos e considerando o preço de venda da energia elétrica gerada pelo sistema. Nota-se que, mesmo considerando a perda de eficiência dos módulos, os mesmos ainda apresentam forte potencial de geração de energia.

TABELA 4. Geração e economia projetadas para os 25 anos do sistema (Autoria própria).

\begin{tabular}{|c|c|c|c|c|c|}
\hline Ano & $\begin{array}{c}\text { Geração } \\
\text { anual } \\
{[k W h]}\end{array}$ & $\begin{array}{c}\text { Receita } \\
\text { bruta } \\
\text { anual }[R \$]\end{array}$ & Ano & $\begin{array}{c}\text { Geração } \\
\text { anual } \\
\text { [kWh] }\end{array}$ & $\begin{array}{c}\text { Receita } \\
\text { bruta } \\
\text { anual }[R \$]\end{array}$ \\
\hline 0 & - & - & 13 & 4751,35 & 1851,51 \\
\hline 1 & 5045,92 & 1966,29 & 14 & 4727,59 & 1842,25 \\
\hline 2 & 5020,69 & 1956,46 & 15 & 4703,96 & 1833,04 \\
\hline 3 & 4995,58 & 1946,68 & 16 & 4680,44 & 1823,87 \\
\hline 4 & 4970,61 & 1936,95 & 17 & 4657,03 & 1814,75 \\
\hline 5 & 4945,75 & 1927,26 & 18 & 4633,75 & 1805,68 \\
\hline 6 & 4921,02 & 1917,62 & 19 & 4610,58 & 1796,65 \\
\hline 7 & 4896,42 & 1908,04 & 20 & 4587,53 & 1787,67 \\
\hline 8 & 4871,94 & 1898,50 & 21 & 4564,59 & 1778,73 \\
\hline 9 & 4847,58 & 1889,00 & 22 & 4541,77 & 1769,84 \\
\hline 10 & 4823,34 & 1879,56 & 23 & 4519,06 & 1760,99 \\
\hline 11 & 4799,22 & 1870,16 & 24 & 4496,46 & 1752,18 \\
\hline 12 & 4775,23 & 1860,81 & 25 & 4473,98 & 1743,42 \\
\hline
\end{tabular}

\section{RESULTADOS E DISCUSSÕES}

Os resultados do estudo de caso realizado na residência escolhida dizem respeito a economia fornecida pelo sistema de geração fotovoltaico proposto e do investimento inicial necessário para a realização do mesmo, além da análise econômica dos investimentos também. Para ser possível iniciar a análise, foi preciso quantificar os custos iniciais para a utilização do sistema fotovoltaico, sendo assim, a estimativa do investimento inicial foi realizada com base nos preços dos equipamentos necessários e da mão de obra necessária para a instalação de tais equipamentos.

O preço das placas solares da marca Canadian Solar modelo CS6P-260P foi tomado como preço médio dentre as variações encontradas no mercado nacional e internacional, assim sendo, encontrou-se o preço médio de R \$778,25, como o sistema proposto conta com 13 módulos fotovoltaicos, o custo total pelos módulos ficou contabilizado em R $\$ 10.117,25$. Já o inversor da marca Phb modelo PHB3000-SS de 3kW de potência possui preço médio na faixa de $\mathrm{R} \$ 6.690,00$ e a mão de obra necessária para a instalação do sistema custa em média R\$ 6900,00, preço médio consultado com empresas privadas especializadas na região de Mossoró. Isto posto, tem-se que o investimento inicial total é de $\mathrm{R} \$ 23.707,25$. 
TABELA 5. Análise do payback simples (Autoria própria).

\begin{tabular}{cccccc}
\hline Ano & $\begin{array}{c}\text { Entradas } \\
{[R \$]}\end{array}$ & $\begin{array}{c}\text { Saldo } \\
{[R \$]}\end{array}$ & Ano & $\begin{array}{c}\text { Entradas } \\
{[R \$]}\end{array}$ & $\begin{array}{c}\text { Saldo } \\
{[R \$]}\end{array}$ \\
\hline 0 & $-23707,25$ & $-23707,25$ & 13 & 1851,51 & 1110,90 \\
\hline 1 & 1966,29 & $-21740,96$ & 14 & 1842,25 & 2953,14 \\
\hline 2 & 1956,46 & $-19784,50$ & 15 & 1833,04 & 4786,18 \\
\hline 3 & 1946,68 & $-17837,82$ & 16 & 1823,87 & 6610,05 \\
\hline 4 & 1936,95 & $-15900,87$ & 17 & 1814,75 & 8424,81 \\
\hline 5 & 1927,26 & $-13973,61$ & 18 & 1805,68 & 10230,49 \\
\hline 6 & 1917,62 & $-12055,98$ & 19 & 1796,65 & 12027,14 \\
\hline 7 & 1908,04 & $-10147,95$ & 20 & 1787,67 & 13814,81 \\
\hline 8 & 1898,50 & $-8249,45$ & 21 & 1778,73 & 15593,53 \\
\hline 9 & 1889,00 & $-6360,45$ & 22 & 1769,84 & 17363,37 \\
\hline 10 & 1879,56 & $-4480,89$ & 23 & 1760,99 & 19124,36 \\
\hline 11 & 1870,16 & $-2610,73$ & 24 & 1752,18 & 20876,54 \\
\hline 12 & 1860,81 & $-749,92$ & 25 & 1743,42 & 22619,96 \\
\hline
\end{tabular}

O critério de avaliação do período de payback simples está relacionado com a vida útil média dos módulos fotovoltaicos, ou seja, para que a utilização da energia solar fotovoltaica na região da cidade de Mossoró seja vantajosa do ponto de vista econômico, o período de payback simples deve ser inferior a essa vida útil, usualmente estimada em 25 anos. Como as receitas anuais não são constantes, não é possível apenas dividir o investimento inicial pelo valor economizado anualmente, dessa forma, foi necessário analisar o saldo do investimento para com o consumidor ano a ano, como mostrado na Tabela 5.

Percebe-se que o payback do investimento acontece entre o ano 12 e o13, então, para encontrar o valor exato do período de payback deve-se subtrair o ano do último saldo negativo do saldo do último ano negativo dividido pela entrada do seguinte. O período de payback encontrado foi de 12,405 anos, equivalente a 12 anos, 4 meses e 25 dias.

Para o cálculo do payback descontado, levando em consideração o dinheiro variando no tempo, faz-se necessário trazer para o valor presente todos os fluxos de caixa do investimento a uma taxa de juros chamada de custo de capital, para este estudo foi utilizado o Índice Nacional da Construção Civil (Sinapi), calculado pelo IBGE, que, para o ano de 2018 foi de $4,41 \%$ [15].

TABEla 6. Análise do payback descontado (Autoria própria).

\begin{tabular}{|c|c|c|c|c|c|c|c|}
\hline Ano & $\begin{array}{c}\text { Fluxo de } \\
\text { caixa }[R \$]\end{array}$ & $\begin{array}{c}\text { Fluxo de } \\
\text { caixa } \\
\text { descontado } \\
{[R \$]}\end{array}$ & Saldo & Ano & $\begin{array}{l}\text { Fluxo } \\
\text { de } \\
\text { caixa } \\
{[R \$]}\end{array}$ & $\begin{array}{c}\text { Fluxo de } \\
\text { caixa } \\
\text { descontado } \\
{[R \$]}\end{array}$ & Saldo \\
\hline 0 & $-23707,25$ & $-23707,25$ & $-23707,25$ & 13 & 1851,51 & 1056,52 & $-5070,69$ \\
\hline 1 & 1966,29 & 1883,24 & $-21824,01$ & 14 & 1842,25 & 1006,84 & $-4063,85$ \\
\hline 2 & 1956,46 & 1794,68 & $-20029,33$ & 15 & 1833,04 & 959,49 & $-3104,36$ \\
\hline 3 & 1946,68 & 1710,28 & $-18319,04$ & 16 & 1823,87 & 914,37 & $-2190,00$ \\
\hline 4 & 1936 & 1629,86 & -166 & 17 & 1814,75 & 871,37 & $-1318,63$ \\
\hline 5 & 1927,26 & 1553,21 & 15135,98 & 18 & 1805,68 & 830,39 & $-488,24$ \\
\hline 6 & 1917,62 & 1480,17 & $-13655,81$ & 19 & 1796,65 & 791,34 & 303,10 \\
\hline 7 & 1908,04 & 1410,56 & $-12245,25$ & 20 & 1787,67 & 754,13 & 1057,23 \\
\hline 8 & 1898,50 & 1344,23 & $-10901,02$ & 21 & 1778,73 & 718,66 & 1775,90 \\
\hline 9 & 1889,00 & 1281,01 & $-9620,01$ & 22 & 1769,84 & 684,87 & 2460,76 \\
\hline 10 & 1879,56 & 1220,77 & $-8399,23$ & 23 & 1760,99 & 652,66 & 3113,43 \\
\hline 11 & & 1163,37 & -723 & 24 & 1752,18 & 621,97 & 3735,39 \\
\hline 12 & 1860,81 & 1108,66 & $-6127,21$ & 25 & 1743,42 & 592,72 & 4328,12 \\
\hline
\end{tabular}

O Analisando a Tabela 6, nota-se que o payback descontado acontece entre o ano 18 e o 19, mais precisamente em 18 anos, 7 meses e 12 dias. 
A última análise a ser realizada é a do Custo da Energia Conservada (CEC), para um investimento ser considerado atrativo com base neste indicador, o valor obtido através do seu cálculo não deve superar o valor do kWh de energia elétrica gerada pelo sistema. A taxa de desconto utilizada para o cálculo do CEC foi a do Índice Nacional da Construção Civil (Sinapi), fixada em 4,41\%, e o custo do kWh utilizado foi o de R \$ 0,38968, valor médio para o ano de 2018 de acordo com os dados da CCE [14].

TABELA 7. Análise do CEC (Autoria própria).

\begin{tabular}{|c|c|c|c|c|c|}
\hline Ano & $\begin{array}{c}\Delta E \\
{[\mathrm{kWh} / \mathrm{ano}]}\end{array}$ & $\begin{array}{c}C E C \\
{[R \$ / k W h]}\end{array}$ & Ano & $\begin{array}{c}\Delta E \\
{[k W h / a n o]}\end{array}$ & $\begin{array}{c}C E C \\
{[R \$ / k W h]}\end{array}$ \\
\hline 0 & - & - & 13 & 4751,35 & 0,33338 \\
\hline 1 & 5045,92 & 0,31392 & 14 & 4727,59 & 0,33506 \\
\hline 2 & 5020,69 & 0,31550 & 15 & 4703,96 & 0,33674 \\
\hline 3 & 4995,58 & 0,31708 & 16 & 4680,44 & 0,33843 \\
\hline 4 & 4970,61 & 0,31868 & 17 & 4657,03 & 0,34013 \\
\hline 5 & 4945,75 & 0,32028 & 18 & 4633,75 & 0,34184 \\
\hline 6 & 4921,02 & 0,32189 & 19 & 4610,58 & 0,34356 \\
\hline 7 & 4896,42 & 0,32351 & 20 & 4587,53 & 0,34529 \\
\hline 8 & 4871,94 & 0,32513 & 21 & 4564,59 & 0,34702 \\
\hline 9 & 4847,58 & 0,32676 & 22 & 4541,77 & 0,34877 \\
\hline 10 & 4823,34 & 0,32841 & 23 & 4519,06 & 0,35052 \\
\hline 11 & 4799,22 & 0,33006 & 24 & 4496,46 & 0,35228 \\
\hline 12 & 4775,23 & 0,33172 & 25 & 4473,98 & 0,35405 \\
\hline
\end{tabular}

Através da Tabela 7 é possível notar que o valor calculado do CEC não ultrapassa o valor de venda do $\mathrm{kWh}, \mathrm{R} \$$ 0,38968, em nenhum dos 25 primeiros anos de funcionamento do sistema. Mesmo sabendo que o valor do kWh é variável no tempo, é importante lembrar que os avanços tecnológicos na área de produção de energia elétrica levam a um cenário otimista onde a tendência é de os investimentos na autoprodução da mesma sejam cada vez mais atrativos.

\section{CONCLUSÃO}

A partir da análise dos resultados apresentados verifica-se que ainda é necessário cautela ao afirmar que investir em energia solar é totalmente viável, trata-se de uma tecnologia que ao passar dos anos vem tornandose cada vez mais acessível graças aos avanços tecnológicos e também graças a quebra de algumas barreiras regulamentárias, como a implementação do sistema de compensação de energia elétrica.

Mesmo com o estudo da análise da viabilidade econômico financeira considerando alguns parâmetros como ideais com o intuito de simplificação, o estudo ainda é bem representativo uma vez que além de considerar o valor do dinheiro ao longo do tempo, considera também o fator de degradação dos módulos fotovoltaicos, que perdem eficiência ao longo de sua vida útil. Após a realização do estudo é possível notar que a utilização de um sistema fotovoltaico é relativamente sensível as tarifas aplicadas ao setor energético brasileiro.

Este trabalho tratou de explanar acerca da tecnologia fotovoltaica sendo inserida no semiárido potiguar, além de ressaltar a importância do investimento em tecnologias para facilitar e impulsionar a geração de energia elétrica através de fontes limpas e renováveis. A viabilidade técnica da utilização de sistemas fotovoltaicos conectados à rede foi claramente atestada durante a execução do trabalho, além do Rio Grande do Norte ser uma região geográfica privilegiada com altos índices de irradiação solar, é possível notar a rápida expansão do setor fotovoltaico na região.

Os resultados apresentados levam a conclusão de que a utilização de energia solar em uma residência que apresenta perfil de consumo mediano é viável do ponto de vista econômico, uma vez que os dois indicadores de payback utilizados, payback simples e o descontado, apresentaram prazo de retorno do investimento inicial inferiores a vida útil média do sistema fotovoltaico, ademais, também foi possível notar através das projeções de caixa para os 25 anos de utilização do sistema que, além de retornar o investimento, ao final dos 25 anos o consumidor terá obtido lucro de aproximadamente $20 \%$ do valor investido inicialmente, considerando o caso do payback descontado, que atenta ao fato do dinheiro variando no tempo. Em relação ao Custo da Energia Conservada (CEC), a análise dos resultados demonstra que a medida é viável economicamente, uma vez que o CEC não ultrapassou o atual valor do kWh em nenhum dos anos de simulação do sistema fotovoltaico, além 
disso, a ascensão atual do mercado fotovoltaico leva a possíveis cenários futuros onde os preços dos equipamentos e da mão de obra se tornem mais baratos, uma vez que mais empresas se instalam no Brasil, e o investimento em tecnologia fotovoltaica se torne cada vez mais atrativo economicamente. Por fim, este trabalho leva a uma melhor compreensão acerca da utilização de energia solar e a posterior análise econômica possibilita compreender melhor os custos de um sistema fotovoltaico e o seu tempo de retorno, revelando que, mesmo em uma região considerada ideal para o uso de tal tecnologia, um estudo prévio de sua viabilidade econômica se faz imprescindível para a tomada de decisão no momento de investir nessa tecnologia.

\section{REFERÊNCIAS}

[1] EMPRESA DE PESQUISA ENERGÉTICA (Brasil). Ministério de Minas e Energia. Balanço Energético Nacional 2018: Relatório Final. Rio de Janeiro: Epe, 2018. 292 p. BRAZILIAN ENERGY BALANCE. Disponível em: <http://www.epe.gov.br/sites-pt/publicacoes-dadosabertos/publicacoes/PublicacoesArquivos/publicacao-303/topico-419/BEN2018_Int.pdf>. Acesso em: 21 jan. 2019.

[2] INTERNATIONAL ENERGY AGENCY (França). Distributed Generation in Liberalised Electricity Markets. Paris, 2002. 124 p. Disponível em: <http://library.umac.mo/ebooks/b13623175.pdf>. Acesso em: 19 jan. 2019.

[3] RÜTHER, Ricardo. Edifícios Solares Fotovoltaicos: O Potencial da Geração Solar Fotovoltaica Integrada a Edificações Urbanas e Interligada à Rede Elétrica Pública no Brasil. Florianópolis: Ufsc/labsolar, 2004. $114 \mathrm{p}$.

[4] II SIMPÓSIO DE ESTUDOS E PESQUISAS EM CIÊNCIAS AMBIENTAIS NA AMAZÔNIA, 2013, Belém. Geração Distribuída: Vantagens e Desvantagens. Belém: Uepa, 2013. 11 p.

[5] SANTOS, Fernando Antônio; SANTOS, Fernando Miguel. Geração Distribuída versus Centralizada, Viseu, n. 35, 15p, Nov. 2008. Disponível em: <http://hdl.handle.net/10400.19/350>. Acesso em: 22 Dezembro 2018.

[6] CEPEL - CENTRO DE PESQUISAS DE ENERGIA ELÉTRICA; CRESESB - CENTRO DE REFERÊNCIA PARA ENERGIA SOLAR E EÓLICA SÉRGIO BRITO, Manual de Engenharia para Sistemas Fotovoltaicos. Rio de Janeiro, RJ, 2014.

[7] AGÊNCIA NACIONAL DE ENERGIA ELÉTRICA. Resolução Normativa Nº 687/2015. 25p.

[8] PEREIRA, E. B. et al., Atlas Brasileiro de Energia Solar. 2.ed. São José dos Campos, 2017. 80 p.

[9] ALMEIDA, Renata Ribeiro Guedes de et al. Proposição de uma metodologia para análise de viabilidade econômica de uma usina fotovoltaica. Revista Principia, João Pessoa, v. 34, p.84-92, maio 2017.

[10] GITMAN, Lawrence J.. Princípios da administração financeira. 12. ed. São Paulo: Pearson Education do Brasil, 2010. 775 p.

[11] MARTINAITIS, V; A ROGOžA,; BIKMANIEN $\doteq$, I. Criterion to evaluate the "twofold benefit" of the renovation of buildings and their elements. Energy And Buildings, [s.1.], v. 36, n. 1, p.3-8, jan. 2004. Disponível em. <http://dx.doi.org/10.1016/s0378-7788(03)00054-9>. Acesso em: 24 Dezembro 2018.

[12] EPE, Empresa de Pesquisa Energética. Anuário Estatístico de Energia Elétrica 2018: Ano base 2017. Rio de Janeiro. 2018. 248 p. Disponível em: <http://www.epe.gov.br/pt/publicacoes-dadosabertos/publicacoes/anuario-estatistico-de-energia-eletrica>. Acesso em: 08 Fevereiro. 2019.

[13] IKUTA JÚNIOR, Emerson Shinji; GOYA, Fernando Takeo. Estudo da Viabilidade tecnico-economica de Sistemas fotovoltaicos interligados à rede elétrica em diferentes cenários de geração. 95 f. TCC (Graduação) - Curso de Engenharia Industrial Elétrica Com Ênfase em Eletrotécnica, Universidade Tecnológica Federal do Paraná., Curitiba, 2014.

[14] CCEE, Câmara de Comercialização de Energia Elétrica. Preços. 2018. Disponível em: <https://www.ccee.org.br/portal/faces/oquefazemos_menu_lateral/precos?_afrLoop=417094191139762 \&_adf.ctrl-state=5f3htv3qh_1\#!\%40\%40\%3F_afrLoop\%3D417094191139762\%26_adf.ctrlstate\%3D5f3htv3qh_5>. Acesso em: 11 Fevereiro 2018.

[15] INSTITUTO BRASILEIRO DE GEOGRAFIA E ESTATÍSTICA IBGE. Indicadores IBGE: Sistema Nacional de Pesquisa de Custo e Índices da Construção Civil. 2019. Disponível em: <ftp://ftp.ibge.gov.br/Precos_Custos_e_Indices_da_Construcao_Civil/Fasciculo_Indicadores_IBGE/sina pi_201812caderno.pdf>. Acesso em: 9 Fevereiro 2019. 